\title{
Configurações
}

Revista de sociologia

\section{Ler o Sul. Os estudos de literaturas africanas em Portugal na década de 80}

Reading the South. Studies on African literatures in Portugal during the 1980s

Lire le Sud. Les études des littératures africaines dans les universités portugaises pendant les années 80

Jessica Falconi

\section{OpenEdition}

\section{Journals}

\section{Edição electrónica}

URL: http://journals.openedition.org/configuracoes/2088

DOI: 10.4000/configuracoes.2088

ISSN: $2182-7419$

\section{Editora}

Centro de Investigação em Ciências Sociais

\section{Edição impressa}

Data de publição: 1 Dezembro 2013

Paginação: 155-166

ISBN: 1646-5075

ISSN: 1646-5075

\section{Refêrencia eletrónica}

Jessica Falconi, «Ler o Sul. Os estudos de literaturas africanas em Portugal na década de 80 », Configurações [Online], 12 | 2013, posto online no dia 12 novembro 2014, consultado o 03 maio 2019. URL : http://journals.openedition.org/configuracoes/2088; DOI : 10.4000/configuracoes.2088

Este documento foi criado de forma automática no dia 3 Maio 2019 


\section{Ler o Sul. Os estudos de literaturas africanas em Portugal na década de 80}

Reading the South. Studies on African literatures in Portugal during the 1980s Lire le Sud. Les études des littératures africaines dans les universités portugaises pendant les années 80

Jessica Falconi

\section{Introdução: literaturas africanas, crítica literária e ideologia}

1 O objetivo deste artigo é analisar alguns aspectos do desenvolvimento da crítica relativa às literaturas africanas de língua portuguesa, com enfoque especial para a literatura moçambicana, a partir de textos críticos da década de 80 - época em que se consolida a institucionalização desta disciplina nas universidades portuguesas. Mais do que traçar uma história factual da disciplina ${ }^{1}$, pretendo abordar um conjunto de textos críticos fundadores de uma área de estudos fortemente marcada por investimentos ideológicos por parte dos agentes envolvidos. Por outras palavras, tal como foi acontecendo em vários contextos intelectuais emergidos da dominação colonial, o domínio do saber - neste caso o domínio da crítica e dos estudos literários - constitui um campo de confrontação entre instâncias ideológicas distintas, cuja abordagem se torna crucial para a atual reflexão em torno da necessidade generalizada de descolonizar o conhecimento em todas as suas facetas.

2 É um dado adquirido que uma parte significativa tanto das literaturas africanas per se, quanto da reflexão crítica sobre tais produções culturais, participou de um projeto intelectual e político de emancipação e de oposição aos discursos de cariz racista e eurocêntrico veiculados pelas ideologias coloniais. Como afirma Simon Gikandi, os conceitos de soberania e autonomia são, de facto, centrais nas literaturas africanas (2007: 
55). Como veremos, principalmente o conceito de autonomia orienta também os momentos fundadores da reflexão crítica sobre as literaturas africanas em português.

Durante a dominação colonial, o exercício crítico de reflexão sobre a literatura e a arte foi uma prática transversal em territórios e línguas distintos, constituindo uma dimensão importante da afirmação política e identitária subjacente ao pensamento e à luta anticoloniais. De acordo com esta perspectiva, podemos afirmar que um corpus notável de crítica literária relativa às produções africanas nasce no domínio extraacadémico, protagonizado por escritores e intelectuais, e veiculado por revistas e jornais ligados aos movimentos anticoloniais ${ }^{2}$.

4 No que se refere às literaturas africanas das então colónias portuguesas, foram fundamentais as atividades culturais promovidas pela Casa dos Estudantes do Império (1944-1965), divulgadas através do boletim oficial Mensagem, bem como as iniciativas editoriais patrocinadas pela mesma instituição ${ }^{3}$. De facto, nas décadas de 50 e 60, principalmente através de artigos de crítica literária publicados nos jornais, e de introduções e prefácios incluídos em coletâneas e antologias, começam a afirmar-se diferentes posições em torno das literaturas africanas escritas em português. Nesse domínio, e nessa época, é incontornável o trabalho de divulgação e reflexão empreendido por Mário Pinto de Andrade, que já em princípios da década de ' 50 levantava questões que viriam a ser centrais para o enquadramento crítico das literaturas africanas, tanto em artigos publicados no boletim Mensagem (Andrade, 1951; 1952), quanto nos textos introdutórios das várias antologias por ele organizadas, como o caderno Poesia Negra de Expressão Portuguesa (1953), compilado em parceria com Francisco José Tenreiro. Mais tarde, as antologias editadas pela CEI, entre as quais Poetas de Moçambique (1962) organizada por Alfredo Margarido, haveriam de dinamizar o debate e alimentar as polémicas em torno das nacionalidades literárias - polémicas que iriam ressurgir ao longo da década de 80 envolvendo críticos e escritores como Alfredo Margarido, Manuel Ferreira, Eugénio Lisboa e Rui Knopfli, entre outros ${ }^{4}$, e que merecem uma análise que não cabe no propósito deste artigo.

\section{História literária, história heroica da Nação: o modelo de Fanon}

No entanto, como é sabido, deve-se a Manuel Ferreira a institucionalização do ensino das literaturas africanas nas universidades portuguesas, devendo-se-lhe também a primeira sistematização do estudo destas literaturas no que se refere ao seu enquadramento histórico-literário. Nesta perspectiva, cabe retomar um breve artigo de Manuel Ferreira para abordarmos um dos esquemas conceptuais mais influentes no dimensionamento histórico-literário das literaturas africanas em questão. Refiro-me ao artigo "Dependência e individualidade nas literaturas africanas de língua portuguesa" ${ }^{5}$. Apesar de se tratar de um texto de pendor mais jornalístico do que propriamente científico, o artigo de Ferreira interessa aqui por esboçar um esquema no qual se torna patente a recepção do influente modelo da evolução das literaturas dos colonizados elaborado por Frantz Fanon.

De facto, em Os Condenados da Terra, Fanon dedica uma parte importante da sua reflexão às práticas literárias e artísticas dos "homens de cultura" ou "intelectuais colonizados", abordando-as a partir do conceito de cultura nacional e da questão da legitimidade da reivindicação nacional. 0 modelo de emergência e desenvolvimento da literatura e da 
cultura no contexto colonial traçado por Fanon teve grande influência nas posteriores configurações críticas das literaturas africanas.

7 Em primeiro lugar, Fanon introduz uma distinção entre os intelectuais e os membros dos partidos políticos, sendo os intelectuais os que realmente se preocupam em dar uma dimensão histórica à cultura nacional por eles mesmos reivindicada em nome do seu povo. Escreve Fanon que:

No seio dos partidos políticos, a maior parte das vezes ao lado deles, aparecem homens de cultura colonizados. Para esses homens a reivindicação de uma cultura nacional, a afirmação da existência dessa cultura, representa um campo de batalha privilegiado. Enquanto os homens políticos inscrevem sua ação no real, os homens de cultura situam-se no quadro da história. (Fanon, 1968: 173-174).

8 Na caracterização dos intelectuais colonizados, Fanon foca principalmente a condição de alienação e distância desses em relação ao povo - alienação analisada também em Peles Negras, Máscaras Brancas. Na visão de Fanon, a procura de elementos culturais não ocidentais, anteriores à imposição da cultura do colonizador, é para esses intelectuais a única estratégia de "retroceder em face da cultura ocidental, na qual correm o risco de submergir" (ibid.: 174). Para Fanon, o passado pré-colonial torna-se o domínio de recuperação da dignidade do sujeito colonizado, já que o colonialismo cumpre com uma "tarefa de desvalorização da história do período anterior à colonização" (ibid.). A recuperação do passado pré-colonial é, para Fanon, estritamente funcional para a legitimação de uma cultura nacional, já que o passado passa a funcionar como justificação do presente e do futuro da consciência nacional. O "mergulho nas entranhas do seu povo" a que se entrega o intelectual colonizado representa então, na leitura de Fanon, a atuação de um "programa coerente" (ibid.: 175-176).

9 Nesta análise, Fanon esboça também uma periodização desse processo de recuperação do passado pré-colonial. Numa primeira fase, a reivindicação de uma cultura negro-africana estrutura-se a nível continental, antes do que nacional, já que funciona como resposta à desvalorização empreendida pelos colonizadores que é igualmente estruturada em prejuízo dos negros como um Todo. Apenas numa segunda fase, os intelectuais passam a delimitar a sua tarefa histórica, assumindo a reivindicação de uma cultura especificamente nacional. A este propósito, Fanon refere tanto o movimento da Negritude, quanto os debates entre escritores africanos e americanos travados nos dois Congressos de Escritores e Artistas Negros, afi rmando que:

A negritude encontrou portanto seu primeiro limite nos fenômenos que justificam a historicização dos homens. A cultura negra, a cultura negro-africana se fragmentou porque os homens que se propunham encarná-la compreenderam que toda a cultura é antes de tudo nacional e que os problemas que mantinham Richard Wright ou Langston Hughes em estado de alerta eram fundamentalmente diferentes daqueles que poderiam desafiar Leopold Senghor ou Jomo Kenyatta. (Ibid.: 178-180)

10 Abordando mais de perto a evolução da produção literária e artística dos intelectuais colonizados - embora sem se cingir a um contexto específico -, Fanon enuncia seu esquema, definindo-o como "um panorama em três tempos":

numa primeira etapa, o intelectual colonizado prova que assimilou a cultura do ocupante. Suas obras correspondem exatamente às dos seus colegas metropolitanos. A inspiração é europeia e pode-se facilmente vincular essas obras a uma corrente bem definida da literatura metropolitana. É o período assimilacionista integral. Encontrar-se-ão nessa literatura de colonizado parnasianos, simbolistas, surrealistas. (Ibid.: 184) 
11 A segunda fase identificada por Fanon corresponde ao fenómeno descrito anteriormente, o "mergulho nas entranhas do povo", ou seja, a tentativa de o intelectual recuperar um patrimônio cultural pré-colonial, percepcionado como depositário de uma autenticidade "nativa". Nesta segunda fase, definida como "literatura de pré-combate", os escritores e intelectuais, já alienados e distantes do seu povo, só podem concretizar o contacto com a cultura negro-africana a partir de um processo de recordação. Relativamente às características mais concretas desta segunda fase, Fanon indica apenas o regresso às lembranças da infância e a releitura de antigas lendas populares. Para este autor, tais características se enquadram num processo mais amplo de recuperação de matrizes culturais pré-coloniais finalizado à construção, por parte do intelectual colonizado, de uma visão dignificada do passado.

12 A terceira fase identificada por Fanon corresponde ao surgimento da literatura de combate, sendo uma fase em que "o colonizado, depois de ter tentado perder-se no povo, perder-se com o povo, vai ao contrário sacudir o povo. Literatura de combate, literatura revolucionária, literatura nacional" (ibid.: 185). Prosseguindo na análise da atuação dos intelectuais em contexto de luta contra a dominação colonial, Fanon expõe os argumentos desenvolvidos também na comunicação ao Segundo Congresso de Escritores e Artistas Negros $^{6}$, defi nindo a vinculação entre cultura nacional e luta anticolonial e, consequentemente, entre a obra cultural empreendida pelos intelectuais colonizados e a luta de libertação em que os povos oprimidos se engajam.

\section{Literaturas africanas em Portugal: modelos histórico-literários}

No intuito de esboçar os traços gerais da evolução das literaturas africanas de língua portuguesa, Manuel Ferreira, no artigo acima mencionado, constrói um modelo semelhante ao "panorama em três tempos" elaborado por Fanon, introduzindo, contudo, algumas diferenças ${ }^{7}$. De facto, a periodização dos contextos de produção literária nas colónias portuguesas em África elaborada por Manuel Ferreira articula-se em quatro momentos principais.

Relativamente à primeira fase, utilizando a mesma linguagem de Fanon, Ferreira aponta para um contexto de alienação em que os escritores limitam-se a imitar os modelos europeus.

Em relação ao modelo em três tempos de Fanon, Ferreira desdobra em duas fases distintas o processo de desalienação e de tomada de consciência dos intelectuais. Na segunda fase, os escritores atingem um menor grau de alienação, conseguindo exprimir um sentimento regionalista e deixando que o meio social, geográfico e cultural influencie o ato da escrita. Ao caracterizar esta fase, Ferreira aponta para a constituição de grupos e a criação de revistas literárias como elementos fundamentais para a emergência de uma consciência nacional integrada na prática literária. Nesta fase, o sentimento regionalista contém os germes de uma iminente consciência nacional. A consciência nacional propriamente dita só se impõe à enunciação literária no terceiro momento, aquando da tomada de consciência da condição de colonizado, que leva o escritor africano à libertação da alienação. É neste momento, para Ferreira, que na escrita se tornam patentes as "raízes profundas da realidade social nacional", sendo que "ao de cima vêm então as características de uma literatura de resistência e de combate" (Ferreira, 1989: 31-32). 
16 Na quarta e última fase, que coincide com a independência nacional, dá-se a libertação completa dos escritores africanos da condição de dependência face ao modelo colonial. Apesar de reconhecer a rigidez do esquema proposto, Ferreira não renuncia à visão teleológica subjacente ao modelo de Fanon: a conquista da independência nacional é o objetivo único e último de grupos e estratos sociais diferentes que, de facto, convergiriam, ao longo dos tempos, para uma coesão necessária, finalizada à inserção da escrita literária na prática política (ibid.: 31-33).

18 A periodização proposta por Manuel Ferreira reflete o paradigma da história literária de cariz narrativo, ou seja, uma história em que um narrador descreve a transição temporal de um estado de coisas para um estado final. Como esclarece Perkins, o modelo narrativo de história literária funda-se no percurso de um "herói" - sujeito coletivo, entidade ideal - narrado a partir de um momento tido como inicial até ao ponto terminal, que coincide, forçosamente, com o presente da narrativa histórico-literária (Perkins, 1992: 29-30).

Também os estudos de Hayden White sobre a escrita da história (1978) têm vindo a iluminar o modo como a construção narrativa do texto historiográfico impõe o uso de metáforas e arquétipos familiares para os leitores. 0 conflito, a luta e a vitória final do "herói" da narrativa funcionam, para o leitor, como elementos de unidade e, consequentemente, de sentido. Na leitura de Perkins, a essência da história literária de cunho narrativo reside na necessidade de excluir qualquer elemento suscetível de desestabilizar a linearidade e unidade da narrativa, isto é, qualquer fator estranho à luta do herói (Perkins, 1992: 43).

Trata-se de um modelo dominante nos estudos de literaturas africanas de língua portuguesa na década de 80 . Na esteira das independências e do clima ideológico da descolonização, a ideia de autonomia - cultural, literária, artística - torna-se um princípio orientador também no campo do saber, e a história literária tem tendência a coincidir, grosso modo, com a trajetória da libertação.

21 No texto intitulado "Les diffi cultés des histoires des littératures des pays africaines de langue portugaise", Alfredo Margarido aborda estas questões discutindo os critérios subjacentes à construção do cânone literário nos países africanos de língua portuguesa, bem como esboçando um outro modelo de periodização para as literaturas em questão (1985: 513-21). No que diz respeito aos critérios de inclusão e exclusão de escritores no corpus das literaturas nacionais, Margarido passa em revista as principais antologias publicadas entre a década de 50 e a de 70. Relativamente às antologias organizadas por Mário Pinto de Andrade, Margarido identifica o critério de construção do corpus no tema da denúncia do colonialismo. Cabe lembrar que, diversamente da opção feita para o caderno Poesia Negra de Expressão Portuguesa, onde não foram incluídos autores caboverdianos, nas outras antologias Pinto de Andrade escolhe juntar autores representativos das cinco então colónias portuguesas em África. A este propósito, Margarido realça que as antologias da CEI, pelo contrário, obedecem ao princípio da autonomia de cada um dos espaços africanos de língua portuguesa. De facto, Margarido escreve que: "Disons-le de façon plus trachante: on voulait prouver par l'organisation des anthologies que chaque pays concerné disposait d'une formulation culturelle autonome, qui n'aurait pu se confondre ni avec les Portugais, ni avec les autres littératures africaines" (ibid.: 518).

Como já foi referido, o conceito de autonomia, declinado de formas diferentes, estrutura a reflexão teórico-crítica, funcionando como denominador comum. Para Fanon e Ferreira, trata-se de identificar o processo de autonomia do escritor/intelectual face à cultura do 
colonizador; para Margarido, trata-se de afirmar a autonomia de cada um dos sistemas literários africanos.

Quanto aos critérios de inclusão e exclusão, Margarido passa em revista diferentes opções, perguntando-se o que define o "escritor africano". Se o critério da cor da pele revela, para Margarido, resquícios de uma abordagem de cariz racista, também os lugares de nascimento ou de residência não são critérios válidos na medida em que não permitem uma organização coerente da matéria.

Do mesmo modo, o critério baseado no engajamento político ao serviço dos movimentos de libertação transformaria a antologia no lugar "de confirmation de la politique du parti unique!" (ibid:: 519).

Em alternativa, Alfredo Margarido aposta na noção de estruturas "tipicamente" nacionais que só se afirmariam de forma inequívoca com a conquista da independência nacional. A proposta de periodização de Margarido articula-se em quatro períodos definidos em relação à trajetória política do colonialismo português. 0 primeiro período começaria a partir da abolição da escravatura e do tráfico para acabar com a proclamação da República em Portugal (1910).

O segundo acabaria com a promulgação do Ato Colonial (1933), a partir do qual começaria um terceiro período até à eclosão da luta armada em Angola, em 1961. O quarto e último período começaria a partir das independências nacionais. Para Margarido, às três primeiras fases correspondem as temáticas da dominação colonial e da sua denúncia, marcadas por motivos recorrentes: o trabalho forçado, a recusa da educação, a ausência de assistência sanitária. A denúncia do colonialismo é portanto o tema principal destas fases, enquanto na quarta e última fase, a literatura já não se estrutura em função do colonizador, mas sim em torno de conteúdos nacionais.

Se por um lado se trata de uma opção que antecipa preocupações até recentes de afirmar a autonomia de cada um dos sistemas literários dos cinco países africanos de língua portuguesa ${ }^{8}$, recusando o agrupamento em função da antiga potência colonizadora comum, por outro lado as antologias da CEI e as posições de Margarido haveriam de funcionar como suportes para a perspectiva nacional e teleológica dos posteriores enquadramentos histórico-literários. Inclusive, a noção do "tipicamente" angolano ou moçambicano não deixa de ser problemática também à luz de debates fundamentais em torno dos conceitos de autêntico, nativo, etc. A este propósito, cabe assinalar brevemente que se trata de debates centrais nos estudos das literaturas do continente africano debates transversais e ao mesmo tempo declinados de forma distinta conforme os contextos culturais, políticos e sociais. De acordo com Adéèkò (2007), de facto, o nativismo tem sido um princípio orientador de diversos discursos críticos, entre os quais lembramos o dos críticos Bolekàjá - Chinweizu, Onwuchekwa e Madubuike -, que na década de 80 publicam o célebre livro-manifesto Toward the Decolonization of African Literature (1983). Para além de reivindicar a necessidade de "indigenizar" os princípios da análise literária, o discurso dos críticos Bolekàjá recusa qualquer instância puramente estética manifestada pelos artistas e escritores africanos, apostando exclusivamente nos aspectos temáticos.

É possível articular esta vertente crítica às polémicas que, na mesma década de 80 , agitam o meio literário moçambicano, aquando da publicação de obras como Monção, de Luís Carlos Patraquim, e sobretudo Vozes Anoitecidas, de Mia Couto. A preocupação estéticoformal dessas obras, entre outras, é alvo de censuras originadas tanto por pressupostos análogos aos que movem os críticos nigerianos Bolekàjá, quanto por posturas rigidamente 
"revolucionárias" que recusam qualquer afastamento da linguagem do povo. Os suplementos literários da revista Tempo, do jornal Notícias, entre outros, tornam-se, de facto, espaços privilegiados para a discussão sobre a função da literatura na nova sociedade revolucionária e sobre as características da moçambicanidade ${ }^{9}$. De modo especial, o conceito de moçambicanidade literária está no cerne de reflexões fundamentais dessa época, nas quais, mais uma vez, as instâncias ideológicas marcam profundamente a prática da crítica literária. Em resposta ao argumento de Manuel Ferreira, para quem "uma verdadeira opção de moçambicanidade [...] não vai ser possível em Moçambique até 1974" (Ferreira, 1977: 81), A. M. Leite e Fátima Mendonça discutem o conceito de moçambicanidade literária a partir de posicionamentos radicalmente distintos. A proposta de Leite (1985) pretende apontar para a necessidade de se fundamentar o conceito de moçambicanidade literária a partir de uma negociação entre paradigmas epistemológicos distintos, tendo em conta também a multiplicidade de matrizes da cultura moçambicana. A partir desta reflexão de Leite, a discussão em torno do cânone literário moçambicano passará a ser encarada cada vez mais em termos de pluralidade, heterogeneidade e indefinição (Matusse, 1998; Rosário, 1996). Em particular, o amplo estudo de Matusse insistirá em redefinir o conceito de moçambicanidade literária em termos anti-essencialistas.

Contudo, ainda na década de $80 \mathrm{e}$ em resposta às teses de Leite, $\mathrm{F}$. Mendonça identifica a referência determinante da moçambicanidade literária no Movimento de Libertação Nacional, que seria "o forjador, por excelência, do conceito de moçambicanidade" (Mendonça, 1985: 36), assumido como princípio ordenador do antes e do depois. Na perspectiva de Mendonça, se a poesia de José Craveirinha e Noémia de Sousa pode ser considerada como fonte originária da ideia de moçambicanidade, ela o é porque "antecipa e profetiza" as possibilidades da luta, reafirmando-se, mais uma vez, o paradigma fanoniano da Nação-Herói da história literária.

\section{Conclusão: histórias literárias em zonas de contacto}

Voltando ao panorama da crítica em Portugal e aos esquemas propostos para enquadrar a produção literária dos países africanos de língua portuguesa, cabe retomar o artigo de Pires Laranjeira "Questões da formação das literaturas africanas de língua portuguesa" (1989) para iluminar um conjunto de questões significativas que marcaram a fase de consolidação dos estudos de literaturas africanas em Portugal, na década de 80.

31 Laranjeira identifica duas tendências estéticas distintas nas literaturas africanas de língua portuguesa "privilegiando ou o realismo ou o abstracionismo, sancionados respectivamente por duas visões quase incompatíveis: a regionalista-nacionalista e a cosmopolita-universalista" (Laranjeira, 1989: 66). Para exemplificar as diferenças entre estas duas vertentes, Laranjeira compara as leituras e referências literárias do poeta moçambicano Rui Knopfli com aquelas de outros escritores africanos, como por exemplo, os cabo-verdianos da chamada geração da Claridade. Principalmente no que diz respeito ao caso da literatura moçambicana, este modelo binário para a interpretação de um panorama literário caracterizado por uma intensa heterogeneidade em termos estéticoideológicos tem sido aplicado até à atualidade. Em particular, a vertente cosmopolita e universalista representada por Rui Knopfli ou, depois da independência, por Luís Carlos 
Patraquim, entre outros, é frequentemente associada à preocupação com a qualidade estético-formal, em detrimento da dimensão temática nacional ${ }^{10}$.

Embora não de forma explícita, no texto de Laranjeira está patente a releitura do modelo de Fanon da evolução das literaturas em contextos de dominação colonial. Tal releitura enriquece este modelo com elementos e fenómenos mais específicos dos espaços africanos de língua portuguesa. Para Laranjeira, o longo percurso de desalienação dos colonizados e de autonomização das literaturas africanas em relação à literatura portuguesa em geral e à literatura colonial em particular, começa a processar-se a partir dos anos 20 e 30 do século XX, com o suporte ideológico do nativismo. Num momento posterior, entre os finais da década de 40 e os da década de 50, para Laranjeira "a consolidação das nacionalidades pré-nacionais entrava a rivalizar com o intercontinentalismo panafricano" (ibid.: 68). Esta fase coincidiria, no modelo de Fanon, com a tomada de consciência dos limites da negritude e do panafricanismo, e com a reivindicação de uma cultura nacional. Contudo, Laranjeira hesita em aderir completamente ao modelo teleológico e narrativo proposto por Ferreira. De facto, cruzando a linha cronológica com a diversificação espacial, a reflexão de Laranjeira realça a multiplicidade de lugares e contextos de enunciação literária existente ao longo da década de 60 , ao colocar o acento em quatro contextos de produção principais:

uma situação de guerrilha com temas daí decorrentes [...]; uma situação de ghetto, localizada nas cidades e prisões coloniais e na metrópole [...]; uma situação de diáspora, com textos escritos e publicados, muitos deles inéditos, em vários países do mundo [...]; uma situação colonialista [...]. (Ibid.: 69)

Lido à luz das profundas mudanças que têm vindo a afetar os estudos literários, com a consequente revisitação do cânone e a crise da historiografia literária tradicional, o modelo espacial proposto por Laranjeira convida-nos, talvez contradizendo as suas intenções iniciais, a repensar as histórias literárias africanas. Cabe, de facto, perguntarmo-nos quais outras narrativas poderão integrar e/ou desconstruir a percepção de uma sequencialidade linear e homogénea da literatura nacional. Por um lado, cartografias mais recentes pretendem focar os interstícios, as margens, os trânsitos e as fronteiras, no intuito de configurar os cruzamentos geográficos e culturais, e/ou o género, a raça, a etnia como loci de enunciação. Loci potencialmente articuladores de histórias literárias em que o próprio conceito de corpus literário nacional, entendido como um todo orgânico e homogéneo, vem perdendo relevância ou vem sendo reconsiderado.

Por outro lado, interrogações análogas são hoje colocadas aos cânones estabelecidos e às categorias utilizadas para descrever e articular o corpus literário nacional numa narrativa historiográfica. Estas tendências recusam, a meu ver, os pressupostos teleológicos do modelo da historiografia literária nacional, e as consequentes produções de histórias literárias orientadas por uma visão excessivamente linear e sequencial dos contextos e das dinâmicas históricas, sociais e culturais em que se enquadram os fenómenos literários. As convulsões teóricas e disciplinares acima mencionadas veiculam abordagens e instrumentos de grande alcance para se perspectivarem os passados literários segundo uma visão menos teleológica e a partir de um olhar mais complexo sobre o modo como se foi estruturando a cultura literária na zona de contacto. Cabe assinalar, por outro lado, que as ferramentas teóricas proporcionadas pelos estudos pós-coloniais têm vindo a originar leituras que pretendem desconstruir o discurso heroico da Nação, privilegiando os elementos dissonantes e ambivalentes das representações literárias ${ }^{11}$. 
Repensar as histórias literárias a partir das zonas de contacto implica, de facto, imaginar outros "lugares", materiais e simbólicos, de produção, circulação e recepção das literaturas africanas. Os estudos transoceânicos, por exemplo, proporcionam um paradigma epistemológico que vem sendo explorado, em tempos mais recentes, no intuito de inserir as literaturas africanas em mapas culturais mais amplos e diversificados ${ }^{12}$, procurando novos pontos de partida para reler os passados literários dos países africanos de língua portuguesa a partir de uma atitude que privilegie a heterogeneidade e a não linearidade. A este propósito, repensar as histórias literárias também à luz dos estudos mais recentes sobre as sociedades coloniais significa reinterpretar tanto o conceito de literatura colonial quanto o corpus que geralmente se inscreve nesta categoria, reconhecendo relações mais complexas e menos dicotómicas com as chamadas literaturas nacionais. Nas palavras de Appiah, trata-se de pôr em relevo as múltiplas heranças dos escritores africanos, bem como a natureza recíproca das relações coloniais e, consequentemente, as inúmeras oportunidades de agenciamento (Appiah, 2007: 250).

\section{BIBLIOGRAPHY}

APPIAH, Kwame Anthony (2007) [1988], “Out of Africa: Topologies of nativism”, in Tejumola Olaniyan \& Ato Quaison (eds.), African Literature: An Anthology of criticism and Theory. Oxford: Blackwell, 242-50.

ANDRADE, Mário Pinto (1951), “A literatura negra e seus problemas”, Mensagem n. 12, 3-5.

ANDRADE, Mário Pinto (1952), “A literatura negra e seus problemas”, Mensagem, n. 13, 14-7.

ANDRADE, Mário Pinto (1953), Poesia Negra de Expressão Portuguesa. Lisboa: CEI.

ADÉÈKÒ, Adèlékè (2007) [1998], "My signifier is more native than yours: Issues in making a literature African", in Tejumola Olaniyan \& Ato Quaison (eds.), African Literature: An anthology of criticism and theory. Oxford, Blackwell, 234-42.

BASTO, Maria Benedita (2006), A Guerra das Escritas. Literatura, nação e teoria pós-colonial em Moçambique. Lisboa: Vendaval.

CHINWEIZU; ONWUCHEKWA, Jemie e MADUBUIKE, Ihechukwu (1983), Toward the Decolonization of African Literature. Whashington D.C.: Howard University Press.

FANON, Franz (1968), Os Condenados da Terra. Rio de Janeiro: Civilização Brasileira.

FALCONI, Jessica (2012), "Literaturas africanas, língua portuguesa e pós-colonialismos”, in Elena Brugioni, Joana Passos, Andreia Sarabando e Maria Manuelle da Silva (orgs.), Itinerâncias. Percursos e representações da pós-colonialidade. Famalicão: Edições Húmus, 203-218.

FERREIRA, Manuel (1989), o Discurso no Percurso Africano. Lisboa: Plátano Editora.

FERREIRA, Manuel (1980), “Dependência e individualidade nas literaturas africanas de língua portuguesa”, Cultura n. 22, 117-123.

FERREIRA, Manuel (1977), Literaturas Africanas de Expressão Portuguesa II. Lisboa: Instituto da Cultura Portuguesa. 
GERARD, Alfred (1980), “The study of African Literature: Birth and early growth of a new branch of learning", Canadian Review of Comparative Literature, Winter, 67-92.

GIKANDI, Simon (2007) [2004], “African literature and the colonial factor”, in Tejumola Olaniyan \& Ato Quaison (eds.), African Literature: An anthology of criticism and theory. Oxford: Blackwell, 54-9.

LARANJEIRA, José Pires (1989), “Questões da formação das literaturas africanas de língua portuguesa”, Colóquio-Letras n. 110/11, 66-73.

LEITE, Ana Mafalda (2010), “Breve história, tópicos e questões sobre o ensino das literaturas africanas de língua portuguesa", Revista Cerrados, n.ำ 30, 75-89.

LEITE, Ana Mafalda (2003), Literaturas Africanas e Formulações Pós-coloniais. Lisboa: Colibri.

LEITE, Ana Mafalda (1985), “Aproximação à moçambicanidade”, in Tempo, 25/6/85, 44-46.

LEITE, Ana Mafalda; CHAVES, Rita; OWEN, Hilary e APA, Livia (orgs.) (2013), Nação e Narrativa Póscolonial I - Angola e Moçambique. Ensaios. Lisboa: Colibri.

MARGARIDO, Alfredo (1985), "Les difficultés des histoires des littératures des pays africains de langue portugaise", in AA.VV. Les Litteratures africaines de langue portugaise. A la recherche de l'identité individuelle et nationale. Paris: Gulbenkian.

MARGARIDO, Alfredo (1963a), “A poesia moçambicana e os críticos de óculos”, Mensagem, Ano XV n. 1, 25-32.

MARGARIDO, Alfredo (1963b), "Do poeta Knopfli à cultura moçambicana”, Mensagem, Ano XV n. 2, $30-49$.

MATESO, Locha (1986), La Litterature africaine et sa critique. Paris: ACCT-Karthala.

MATUSSE, Gilberto (1998), A Construção da Imagem da Moçambicanidade em José Craveirinha, Mia Couto e Ungulani Ba Ka Khosa. Maputo: Imprensa Universitária.

MENDONÇA, Fátima (2008), "Literaturas emergentes, identidade e cânone”, in M. C. Ribeiro e M. P. Meneses (orgs.), Moçambique: das palavras escritas. Porto: Afrontamento, 19-34.

MENDONÇA, Fátima (2008), “Literatura moçambicana: o que é?”, in Tempo, 7/7/85, 34-36.

NOA, Francisco (2008), “Literaturas Moçambicana: os trilhos e as margens”, in M. C. Ribeiro e M. P. Meneses (orgs.), Moçambique: das palavras escritas. Porto: Afrontamento, 35-46.

MONTEIRO, M. R. Valente Sil (2011), C.E.I. Celeiro do Sonho. Geração da "Mensagem". Braga: Cehum. PERKINS, David (1992), Is Literary History Possible?. Baltimore: Johns Hopkins UP.

ROSÁRIO, Lourenço do (1996), Singularidades. Estudos Africanos. Lisboa: Edições Universitárias Lusófonas.

WHITE, Hayden (1978), Tropics of Discourse. Baltimore: Johns Hopkins UP.

\section{NOTES}

1. Veja-se a este propósito, entre outros, Ferreira, 1989; Leite, 2010.

2. A este propósito, são emblemáticos os debates em torno do papel de intelectuais, artistas e escritores nas sociedades africanas, quer durante a dominação colonial, quer depois das independências. Dão conta destes debates, por exemplo, as resoluções e os textos das Conferências dos Escritores Afro-Asiáticos $(1958,1962,1967,1970)$ e os Congressos de Escritores e Artistas Negros (1956, 1959). Cabe sublinhar também o papel das revistas literárias, 
principalmente da revista Presence africaine. Sobre o papel desta revista no domínio da crítica literária, são emblemáticas as palavras de Locha Mateso: “c'est surtuout par ses chroniques, ses comptes rendus, ses notes de lecture et ses tables rondes que le journal d'Alioune Diop s'est révélé être le creuset d'une certaine conscience critique" (1986: 116). Sobre os primórdios da crítica literária de cariz jornalístico, ver também Gérard (1980).

3. Sobre o Boletim Mensagem e as atividades da CEI, ver Laranjeira (1992) e Monteiro (2011).

4. Sobre o que podemos considerar como a primeira fase das polémicas sobre nacionalidades literárias, vejam-se, por exemplo, o prefácio de Margarido à antologia Poetas de Moçambique (1962) e os artigos do mesmo autor publicados em Mensagem (1963 $\left.{ }^{\mathrm{a}}, 1963 \mathrm{~b}\right)$.

5. Originariamente publicado em Cultura n. 22, abril 1980, pp. 117-23, o texto foi posteriormente revisto e incluído em Ferreira, 1989.

6. Comunicação incluída em Os Condenados da Terra com o título "Fundamentos recíprocos da cultura nacional e das lutas de libertação".

7. Cabe assinalar que no texto "Da pertinência ou não pertinência da designação de "literatura negra”, também incluído em 0 Discurso no Percurso Africano, Ferreira refere o modelo de Fanon em termos que mostram a sua intenção de revisitar tal modelo: "Franz Fanon articulou muito bem os três períodos da evolução do homem negro na época colonial - europeísmo, exotismo, africanidade - embora a sua descrição não possa ser literalmente aplicada ao espaço africano que foi colonizado pelos portugueses. Isso, porém, não invalida a pertinência do seu esquema, e a possibilidade de se verificar a incidência e extensão das suas coordenadas" (1989: 84).

8. Veja-se, por exemplo, Leite (2003).

9. A este propósito, ver principalmente Basto (2006) e Mendonça (2008).

10. Veja-se, por exemplo, Mendonça (2008) e Noa (2008).

11. No que se refere às literaturas africanas de língua portuguesa, veja-se, por exemplo, Leite et al. (2013).

12. Para uma breve revisão bibliográfi ca dos estudos das literaturas africanas de língua portuguesa centrados no espaço atlântico e índico, ver Falconi (2012).

\section{ABSTRACTS}

O objetivo deste artigo é focar alguns aspectos do desenvolvimento da crítica relativa às literaturas africanas de língua portuguesa, a partir de textos críticos da década de 80 - época em que se consolida a institucionalização desta disciplina nas universidades portuguesas. Mais do que traçar uma história factual da disciplina, pretendo abordar um conjunto de textos críticos fundadores de uma área de estudos fortemente marcada por investimentos ideológicos por parte dos agentes envolvidos. Por outras palavras, tal como foi acontecendo em vários contextos intelectuais emergidos da dominação colonial, o domínio do saber - neste caso, o domínio da crítica e dos estudos literários - constitui um campo de confrontação entre instâncias ideológicas distintas, cuja abordagem se torna crucial para a atual reflexão em torno da necessidade generalizada de descolonizar o conhecimento em todas as suas facetas.

The aim of this article is to look at some aspects of the development of literary criticism related to African literatures written in Portuguese. My study makes use of literary criticism written in the 1980s, the period when African literature studies became an established course in Portuguese universities. However, instead of tracking the history of this subject, this paper focuses on a 
number of sample texts that helped establish this area, which is strongly marked by different ideological points of view. In other words, as was happening other postcolonial intellectual contexts, the realm of knowledge (in this case literary criticism) is an area of conflict between different ideological positions, including literary criticism and literary studies. I believe that this kind of approach is necessary to consider the different needs for decolonizing knowledge in all its facets.

Le but de cet article est d'examiner certains aspects du développement de la critique des littératures africaines en langue portugaise, en commençant par une série de textes critiques écrits dans les années 80, qui sont une période au cours de laquelle l'introduction de ces disciplines dans les universités portugaises a été consolidée. Plutôt que de décrite une histoire de cette discipline, je suis intéressée par l'analyse d'un ensemble de textes " fondateurs " d'un domaine d'étude fortement marqué par des investissements idéologiques de la part des agents impliqués. En d'autres termes, de façon similaire à ce qui s'est passé dans divers contextes intellectuels qui ont émergé de la domination coloniale, le champ de la connaissance - dans ce cas, la portée de la critique et des études littéraires - se transforme en un champ de comparaison entre les différentes positions idéologiques. Analyser cette comparaison est à mon avis essentiel pour réfléchir à la nécessité généralisée de " décoloniser " les nombreux aspects de la connaissance.

\section{INDEX}

Mots-clés: Littératures africaines, critique littéraire, universités portugaises

Keywords: African literatures, literary criticism, Portuguese universities

Palavras-chave: literaturas africanas, crítica literária, universidades portuguesas

\section{AUTHOR}

\section{JESSICA FALCONI}

Centro de Estudos Sociais

jessicafalconi@ces.uc.pt 